\title{
EFFECTS OF ALCOHOL; COGNITIVE DISTURBANCES, PESSIMISM, DEPRESSIVE SYMPTOMS AND PSYCHOLOGICAL MALADJUSTMENT AMONG ALCOHOLICS
}

1. MS Clinical Psychology Unit, Government College University, Lahore

2. Ph.D. Associate Professor of Psychology,

Head of Department of Applied Psychology,

Government College Township, Lahore

\section{Correspondence Address:}

Dr. Fauzia Naz, Ph.D.

Associate Professor of Psychology, Head of Department of Applied Psychology,

Government College Township, Lahore

drfauzianaz@hotmail.com

Article received on: 28/03/2016

Accepted for publication:

03/05/2016

Received after proof reading: 26/05/2016

\begin{abstract}
Hira Aziz', Dr. Fauzia Naz ${ }^{2}$
ABSTRACT... Objectives: The present study examined the effects of alcohol consumption on cognitive failures, depressive symptoms, pessimism and psychological maladjustment among alcoholics. The research further explored predictive relationship between cognitive disturbances, depressive symptoms, pessimism and psychological maladjustment in alcoholics. Study Design: Between-groups correlational research design. Settings: Lahore city. Method: A sample of 33 men and 4 women (age: 20-60 years) who were addicted to alcohol were recruited. Equal number of comparison group who do not use alcohol, matched on age, gender and socioeconomic status were recruited. Cognitive Failure Questionnaire ${ }^{1}$, Personality Assessment Questionnaire ${ }^{2}$, Life Orientation Test ${ }^{3}$ and Centre for Epidemiological Scale for Depression Scale ${ }^{4}$ were used as assessment measures. Results: Results of the study showed that alcoholics had higher scores on cognitive failures, depressive symptoms, pessimism and psychological maladjustments as compare to the non-alcoholics. There was a significant predictive relationship between cognitive failures, pessimism, depressive symptoms and psychological maladjustment. Results of AMOS show model fit with cognitive failure, depressive symptoms and pessimism as significant predictors of different dimensions of psychological maladjustment among alcoholics.
\end{abstract}

Keywords: Cognitive failure, depressive symptoms, psychological maladjustment, alcoholic

Article Citation: Aziz H, Naz F. Effects of alcohol; cognitive disturbances, pessimism, depressive symptoms and psychological maladjustment among alcoholics. Professional Med J 2016;23(6):680-686. DOI: 10.17957/TPMJ/16.3377

\section{INTRODUCTION}

Alcoholism is the term mostly used to describe alcohol dependence that is associated with severe consumption of alcohol, abusive use of alcohol and leads towards drinking pattern through impulsivity. ${ }^{5}$ Diagnostic and Statistical Manual of Mental Disorders ${ }^{6}$ by American Psychiatric Association (APA) names alcoholism as alcohol use disorder and alcohol intoxication which is defined as a problematical form of alcohol consumption leading to clinically significant impairment or distress for at least twelve months period. Alcohol use disorder covers consumption of heavy amount of alcohol, craving and extra urge to drink alcohol which ultimately subsequent in incapable to accomplish major role obligation in many areas of life i.e., occupational, social, interpersonal problems. Recreational activities are also disrupted. The person cannot help himself/herself drinking alcohol even if there are physical hazardous.

Alcohol dependence is assisted by the severe consumptions of alcohol. The abusive use of alcohol, leads a person towards drinking pattern through impulsivity. ${ }^{6}$

Abnormal alcohol usage patterns including severe consumption can have devastating effects on the body and brain functioning including memory deficits or loss, problems in storing and executive functioning of central nervous system. Wernicks' syndrome and Karasoffs' syndrome could be the most severe consequences. ${ }^{7}$

The psychological consequences of chronic patterns of alcohol consumption can be developing symptoms of depression and distress. Alcohol use disorder is often associated with symptoms of depression, anxiety and many of 
the maladjusted behaviors. Associated with both morbidity and mortality, depression is a major public health problem throughout the world and is characterized by lowered mood, loss of capacity to experience pleasure, increased sense of worthlessness, fatigue, and preoccupation with death and suicide. .,9,10 $^{8}$

In a longitudinal study by ${ }^{11}$, the researchers explored effects of late middle aged adults' drinking behavior on their subsequent 10-year depressive symptoms. They recruited 7939 adults who were regular consumers of alcohol and assessed them twice in a year for ten years on their depressive symptoms. The researchers found association of subsequent long-term course of alcohol consumption with their depressive symptoms.

Pessimism is a state of mind or disposition in which the person anticipates undesirable outcomes or believes that the evil or hardships in life outweigh the good. The pessimism disposition had effects on all major areas of thinking. ${ }^{10}$ Scheier and Carver's (1985) ${ }^{12}$ model of optimism/pessimism suggests that pessimism contains traits like tendencies to hold negative experiences about the future. Pessimistics may avoid goal-directed activities because of negative expectations. ${ }^{13}$ Studies related to pessimism and substance abuse are scarce but some studies have examined associations between pessimism and drugs. Some of the epidemiological studies found morbidity of anxiety and depressive symptoms in addition to legal, social and occupational problems in people who excessively consume alcohol ${ }^{14,15}$ which turn into maladaptive behavior as well ${ }^{16}$ because when individuals do not able to fulfill the responsibilities then it creates a stress in which indirectly develop depressive feature in them. ${ }^{17}$ Studies ${ }^{13}$ with longitudinal data described significant link between alcohol and alcohol dependence and major depressive disorder. Literature suggest that alcohol dependence is more predictor of major depressive disorder as compare to major depressive act as contributor of alcohol dependence. ${ }^{18}$ Maladaptive behavior is defined as psychological maladjustment which is associated with dependency, negative self-esteem, negative self-efficacy, emotional unresponsiveness, emotional instability and negative world view. ${ }^{2}$

Pakistan, being an Islamic country prohibits every type of drug consumption by state law and by religion as well. But opposite to this, many segments of society are involved in drug abuses including consumption of alcohol. ${ }^{19}$

\section{OBJECTIVES}

Objectives of the study included exploring differences between alcoholics and nonalcoholics regarding cognitive failures, psychological maladjustment, pessimism and depressive symptoms. Further, the research also explores predictive relationships between cognitive failures, psychological maladjustment, pessimism and depressive symptoms among alcoholics.

\section{Hypotheses of study}

Following hypotheses were included:

1. There is likely to be differences between alcoholics and non-alcoholics related to cognitive failures, psychological maladjustment, pessimism and depressive symptoms.

2. There is likely to be predictive correlation between cognitive failures, psychological maladjustment, pessimism and depressive symptoms among alcoholics.

\section{METHOD}

\section{Research design}

The present study used a correlational betweensubjects research design.

\section{Participants}

Sample included 33 men and 4 women who use alcohol. Equal number of comparison group was included who do not use alcohol or any other drugs which also include smoking. Both the groups were matched on age, gender and socioeconomic status. The age range of the sample was between 20-60years. Inclusion criteria for the sample who use alcohol were recruiting 
only those persons who drink alcohol regularly, who take alcohol and smoke simultaneously and who do not have any diagnosed psychological disorder. Those alcoholics were excluded who use multiple types of drugs along with alcohol, who use alcohol once in a while or occasionally and those who were non-Muslims. Majority 30 (81 $\%$ ) of the sample was post-graduate and 7 (19\%) were graduate. 25 were married and 12 were unmarried. Frequency of the alcohol consumption was reported 21 servings weekly.

\section{ASSESSMENT MEASURES}

\section{Cognitive Failure Questionnaire (CFQ1)}

CFQ is used to assess self-reporting failures in perception memory and motor functions. CFQ is a 25 item Likert-type scale and the response options range from "very often (4)" to "never (0)". Cronbaches' alpha reliability of the scale for the present research was excellent i.e., .95.

\section{Life Orientation Test (LOT) 3}

LOT is a 10 items scale that assesses optimism (3 items) and pessimism (3 items) in personality. Respondent rate items on a five points Likert-type scale i.e., strongly agree, disagree, neutral, agree and strongly disagree. The Chronbach's alpha reliability of LOT is .81 for the present research.

\section{Centre for Epidemiological Studies for Depression Scale (CES-D4)}

CES-D is a 20 items scale used to assess the severity of depressive symptoms in adults. Items are arranged on likert type scale that ranges from 0 to 3 point. The scale had .85 chronbach's alpha reliability for the present research.

Personality Assessment Questionnaire (PAQ2) $P A Q$ is a 42 item Likert-type scale use to assess psychological maladjustment. The response options range from almost always not true to almost always true. PAQ assess personality maladjustment on seven personality dimensions i.e., dependency, negative self esteem, negative self efficacy, emotional unresponsiveness, emotional instability and negative world view. Chronbach's alpha reliability of the scale for the present research was excellent i.e., .89.

\section{Demographics}

Demographic information included sex, age, religion, marital status, education, physical disability if any, any diagnosed psychological disorder. Questions about consumption of alcohol included taking information about the frequency of alcohol intake per week.

\section{Procedure}

After finalizing assessment measures and permission process, sample was approached. As sample was collected through snow-ball sampling and personal contacts, participants were recruited from Pearl Continent bars, James $n$ Java cafes, Pakistan Institute of Mental Health rehabilitation centers and Lahore Gymkhana club. Participants were informed about the objectives of the research and their informed consent was taken. They were assured about the anonymity and confidentiality of information. Initially, 45 men gave consent to participate in the study, but only 33 men (73\%) completed the questionnaires. Out of 16 women, only $4(25 \%)$ completed the questionnaires. The reasons for quitting from participation were included non-serious attitude and lack of time for men and fear of being exposed (concerns about confidentiality/anonymity) for women. Data were collected, analyzed and discussed.

\section{RESULTS}

To see differences between alcoholics and non-alcoholics related to cognitive failure, psychological maladjustment, pessimism and depressive symptoms, the t-test analysis was done and the results are presented in Table-l.

Results revealed significant differences between alcoholics and non-alcoholics related to cognitive failure, psychological maladjustment, pessimism and depressive symptoms. Mean scores show that alcoholics had higher mean scores on cognitive failures, psychological maladjustments, pessimism and depressive symptoms as compare to non-alcoholics.

To see predictive correlation between cognitive failures, psychological maladjustment, pessimism and depressive symptoms among alcoholics. 
Pearson correlational analysis was done. The results are presented in Table-II.

Results showed significant relationship between cognitive failures, depressive symptoms, pessimism and psychological maladjustment.

Finally, we tried to see cognitive failures, depressive symptoms and pessimism as predictors of psychological maladjustment. Stepwise regression analyses was employed and results are presented in Table-III.

Results revealed that regression analysis worked out in two steps. In step 1, cognitive failures and depressive symptoms emerged as significant predictors of psychological maladjustment accounting for twenty-nine percent of the variance.
In the second step, cognitive failures, depressive symptoms and pessimism emerged as significant predictors of psychological maladjustment. These variables accounted for twenty-two percent of the variance.

Internal validity of results and Model Fit through Analysis of Moment Structure (AMOS) Results were validated by applying fitting a model through AMOS. AMOS requires the criteria for model fit i.e., CFI (Comparative Fit Index) >.90; GFI (Goodness of Fit Index) > .90; $\mathrm{NFI}$.90; REMSEA (Root Mean Square Error of Approximation) $<.05$.

For the present study, the values of CFI, GFI, NFI and REMSEA show perfect model fit. The results are presented in table given below

\begin{tabular}{|l|c|c|c|c|c|c|c|}
\hline \multicolumn{1}{|c|}{ Variables } & Alcoholics & \multicolumn{2}{|c|}{ Non-Alcoholics } & & \\
\hline & M & SD & M & SD & t(df) & p & Cohan's d \\
\hline Cognitive failure & 51.8 & 18.8 & 33.6 & 19.8 & $4.00(72)$ & .000 & 0.94 \\
\hline Psychological Maladjustment & 154.5 & 21.9 & 139.2 & 15.1 & $3.4(72)$ & .000 & 0.81 \\
\hline Pessimism & 27.8 & 11.6 & 19.4 & 10.5 & $4.00(72)$ & .000 & 0.89 \\
\hline Depressive Symptoms & 25.9 & 11.9 & 16.7 & 7.1 & $5.56(72)$ & .000 & 0.938 \\
\hline
\end{tabular}

Table-I. Mean differences of Alcoholics and Non-Alcoholic on Cognitive Failure, Psychological Maladjustment, Pessimism and Depressive Symptoms

\begin{tabular}{|l|c|c|c|c|c|}
\hline \multicolumn{1}{|c|}{ Variables } & $\mathbf{1}$ & $\mathbf{2}$ & $\mathbf{3}$ & $\mathbf{4}$ & $\mathbf{M}$ (SD) \\
\hline 1-Cognitive failures & $.35^{\star \star}$ & $.22^{\star}$ & $.37^{\star \star}$ & $.42^{\star \star}$ & $42.7(21.2)$ \\
\hline 2-Depressive symptoms & - & $.21^{\star}$ & $.32^{\star \star}$ & $.26^{\star \star}$ & $21.3(10.8)$ \\
\hline 3-Pessimism & & - & $.29^{\star \star}$ & $.39^{\star \star}$ & $11.1(4.3)$ \\
\hline 4-Psychological maladjustments & & & - & $.32^{\star \star}$ & $146.8(20.2)$ \\
\hline
\end{tabular}

Table-II. Pearson Correlation between Cognitive failures, depressive symptoms, Psychological Maladjustment Alcoholics $(n=74)$

Note. ${ }^{*} p<.05 .{ }^{* *} p<.01$.

\begin{tabular}{|c|c|c|c|c|c|c|c|}
\hline Predictors & $\boldsymbol{\beta}$ & $\mathbf{R}^{2}$ & $\Delta \mathbf{R}^{2}$ & Predictors & $\boldsymbol{\beta}$ & $\mathbf{R}^{2}$ & $\Delta \mathbf{R}^{2}$ \\
\hline Step 1 & & & & Step 2 & & & \\
\hline Cognitive failures & $.44^{\star \star \star}$ & $.29^{* *}$ & $.29^{* *}$ & Cognitive failures & $.33^{* *}$ & $.22^{* *}$ & $.22^{\star \star}$ \\
\hline Depressive symptoms & $.30^{\star *}$ & & & Depressive symptoms & $.28^{\star *}$ & & \\
\hline & & & & Pessimism & $.24^{\star \star}$ & & \\
\hline
\end{tabular}

Table-III. Regression Analyses to see Cognitive Failures, Depressive Symptoms and Pessimism as predictors of Psychological Maladjustment $(n=74)$

Note. ${ }^{* *} p<.01 .{ }^{* *} p<.001$.

\begin{tabular}{|l|c|c|c|c|c|c|}
\hline Model & $\chi^{2}$ & Df & CFI & GFI & NFI & REMSEA \\
\hline Default & 3.41 & 3 & .99 & .98 & .98 & .04 \\
\hline
\end{tabular}




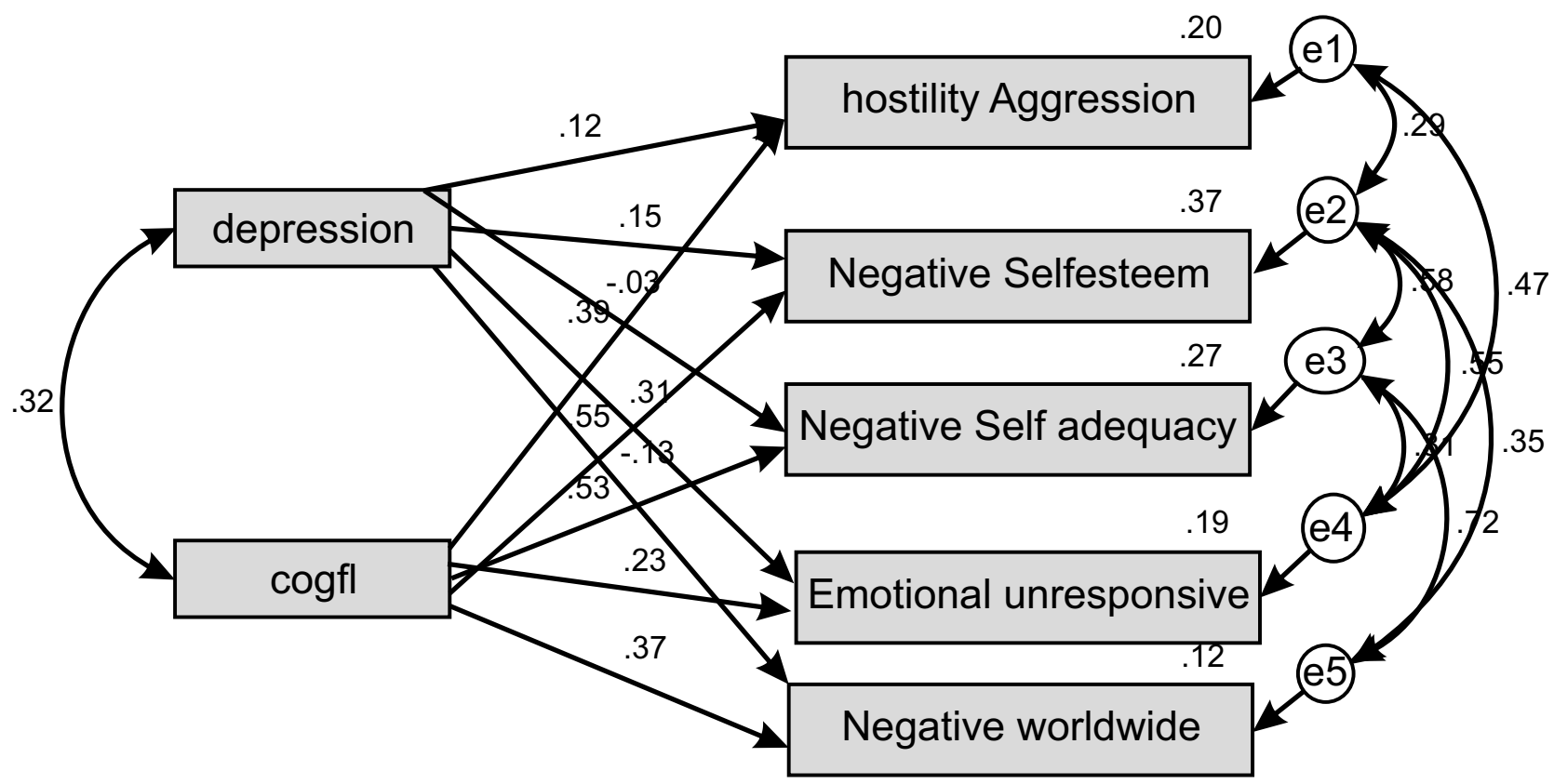

The model shows that cognitive failure and depressive symptoms emerged as significant predictors of psychological maladjustment which had seven dimensions i.e., hostility/aggression, negative self-esteem, negative self-adequacy, emotional unresponsiveness and negative worldview. The model endorse the results of regression analysis.

\section{DISCUSSION}

The current study explored differences regarding cognitive failures, pessimism, depressive symptoms and psychological maladjustment between alcoholics and non-alcoholics. Further, the research tried to explore predictive relationship between cognitive failures, pessimism, depressive symptoms, and personality maladjustment among alcoholics. For the first aim, the results revealed significant differences in the mean scores of alcoholics and non-alcoholics on cognitive failures, pessimism, depressive symptoms and psychological maladjustment. Mean scores of alcoholics was significantly higher than those who do not addicted to alcohol. The results from the present study are in line with those of Abramson, Metalsky and Alloy ${ }^{20}$ indicated that feelings of loss of meaningfulness (cognitive disturbances) in everyday tasks and a persistent negative affect and serious affective dysfunctions mainly depression are characteristics of individuals who use alcohol. Similarly, the relation between cognitive failures, depressive symptoms and maladjusted behavior is confirmed by different studies. ${ }^{21}$ Some of the previous literature revealed gender differences regarding personality maladjustment in psychological and emotional adjustment and adaptive resources of life. The findings of the study reported a significant difference in high negative effect of maladjustment in men and women who use alcohol. ${ }^{10}$

The results from the present study revealed significant predictive relationship between cognitive failures, pessimism, depressive symptoms, and personality maladjustments among alcoholics. These results are in line with the findings of a research conducted by Kahler, Read, Wood and Paflai (2003) as the researchers found significant relationship between alcoholism and personality traits leading to maladjustment. In another study ${ }^{5}$, the researchers found significant relationships between alcoholism and depressive symptoms in middle aged men and women.

Similarly, these results are endorsed with the results in a study ${ }^{22}$ in which the researchers found 
that depressive symptoms lead to psychological maladjustment and found strong association between depressive symptoms psychological maladjustment. In another study, Lee ${ }^{23}$ explored sense of belongingness, resilience and depressive symptoms among alcoholics and non-alcoholics. The findings revealed that on depressive symptoms, alcoholics scored significantly higher than non-alcoholics. A study was conducted to see certain personality dimension of alcoholics leading towards maladjustment. The findings of study revealed that alcoholics scored high on assessing impulsivity as compared to nonalcoholics.

\section{CONCLUSION}

To sum up, present study has served s number of purposes, such as exploring the use of alcohol, influence of alcohol on different dimensions of personality as developing depressive symptoms, cognitive failures and maladjustment. In Pakistan, scarce literature and research is available on studying the direct effects of alcohol on the alcoholics due to the difficulties in accessibility of sample. The current study found that the individuals who use alcohol had high cognitive failures, pessimism, depressive symptoms and psychological maladjustment. Cognitive failures and depressive symptoms emerged as significant predictors of psychological maladjustment among alcoholics.

\section{Limitations}

Sample was not easily available. The recruitment of sample especially women who used alcohol was very difficult as many of the women denied to participate due to the fear of disclosure.

Copyright@ 03 May, 2016.

\section{REFERENCES}

1. Broadbent DE, Cooper PF, FitzGerald P, Parkes KP. The Cognitive Failure Questionnaire (CFQ) and its correlates. Br J Clin Psychol. 1982; 21:1-16.

2. Rohner R P, Khaleque A. Handbook for the study of parental acceptance and rejection ( $4^{\text {th }}$ ed.). 2005; Storrs, CT: Rohner research publications.

3. Scheier MF, Carver CS. Effects of optimism on psychological and physical well-being:
Theoretical overview and empirical update. Cognitive Therapy and Research. 1992; 16, 201-228.

4. Radloff LS. The CES-scale: A self-report depression scale for research in the general population. Applied Psychological Measurement.1977; 1, 385-401.

5. Caan, Wood. Drink, Drugs and Dependence: From Science to Clinical Practice (1 ${ }^{\text {st }}$ ed). Routledge. 2002; Pp. 19-20. ISBN 978-0-415-27891-1.

6. American Psychiatric Association. Diagnostic and statistical manual of mental disorders (5 $5^{\text {th }}$ ed.). 2013; Arlington, VA: American psychiatric publishing.

7. Parsons N, Butters P, Nathan N. Neuropsychology of alcoholism: Implications for diagnosis and treatment. 1987; Guilford Press, Newyork.

8. Abas $M$, Broadhead J. Mental disorders in the developing world. BMJ 1994; 308:1052-3.5.

9. Everson SA, Roberts RE, Goldberg DE, et al. Depressive symptoms and increased risk of stroke mortality over 29 years. Arch Intern Med 1998; 158:1133-8.

10. Davidson KM. (1995) Diagnosis of depression in alcohol dependence: changes in prevalence in drinking status. British Journal of Psychiatry. 1995; 166:199-204.

11. Brennan LP, SooHoo S, Lemake S, Schutte KK. Alcohol Use Predicts 10-Year Depressive Symptom Trajectories in the Health and Retirement Study. J Aging Health. 2015; doi; 0898264315615837.

12. Scheier MF, Carver CS. Optimism, coping, and health: Assessment and implication of generalized outcome expectancies. Health Psychology. 1985; 4,219-247.

13. Thompson A, Gaudreau P. From optimism and pessimism to coping: The mediating role of academic motivation. International Journal of Stress Management. 2008; 15, 3, 269-288.

14. Reich T, Edenberg HJ, Goate A, Williams JT, Rice JP, Van Eerdewegh P, Begleiter H. Genome-wide search for genes affecting the risk for alcohol dependence. American Journal of Medical Genetics, 1998; 81(3), 207-215.

15. American Psychiatric Association. Diagnostic statistical manual of mental disorders ( $4^{\text {th }}$ ed., text rev.).2000; doi:10.1176/appi.books. 9780890423349.

16. Fregusson DM, Boden JM, Horwood IJ. Tests of casual links between alcohol abuse or dependence and major depression. Archives of general psychiatry. 2009; 66(3); 260-6. 
17. Grant BF, Dawson DA, Stinson FS, Chou PS, kay W, Pickering $R$. The alcohol use disorder and Associated Disabilities Interview Schedule-IV (AUDADISIV): Reliability of alcohol consumption, tobacco use, family history of depression and psychiatric diagnostic modules in a general population sample. Drug and alcohol dependence, 2003; 71(1), 7-16.

18. Flansborg M T. Comorbidity and temporal ordering of alcohol use disorders and other psychiatric disorders. Comp. Psychiartry 2009; 50,307-14. Doi:10.1016/J.comppsych.2009.09.003.

19. Naz, F. (2016). Cannabis (bhang, charas) consumption, emotional and cognitive disturbances and depressive symptoms in young adults" Accepted for publication in The Professional Medical Journal.
20. Abramson LY, Metalsky GI, Alloy LB. Hopelessness Depression: A theory-base subtype of depression. Psychological Review, 1989; 96, 358-372.

21. Wagle AC, Berrios GE, Ho L. (1999). Cognitive failures questionnaire in psychiatry. Comprehensive psychiatry, 1999; 40,478-484.

22. Naz F, Kausar R. Parental Rejection, Personality Maladjustment and Depression Symptoms in Female Adolescents in Pakistan. Journal of humanities and social Science. 2013; 14, 1.

23. Lee $H$. Relationships among parental alcoholism, sense of belonging, resilience and depressive symptoms in Korean people. 2010; University of Michigan.

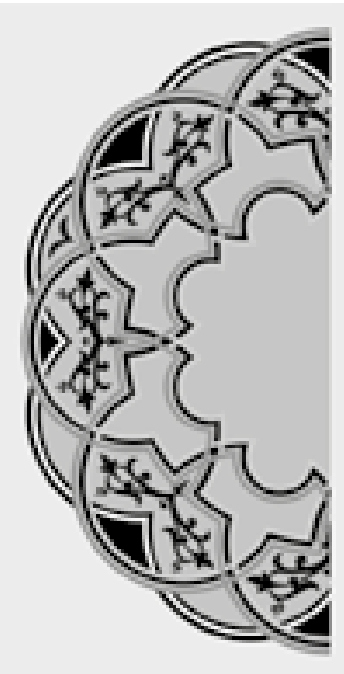

\title{
"SMALL changes can make a BIG difference."
}

\author{
Unknown
}

\section{AUTHORSHIP AND CONTRIBUTION DECLARATION}

\author{
Sr. \# \\ 1 Hira Aziz
}

2 Dr. Fauzia Naz
Contribution to the paper

Conceived, Designed and collected data, Analyzed data, Results, discussion and references.

Supervised thesis, Analyzed the data and prepared complete manuscript
Author $=\mathbf{s}$ Signature
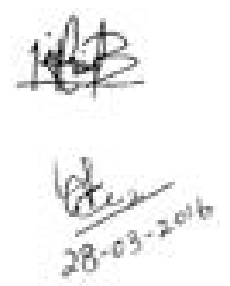